\title{
Re-isolation of Wuxiang Virus from Wild Sandflies Collected from Yangquan County, China
}

\author{
Qinyan Wang ${ }^{1,2} \cdot$ Shihong $\mathrm{Fu}^{2} \cdot$ Jingxia $\mathrm{Cheng}^{3} \cdot \mathrm{Xiuyan}^{\mathrm{Xu}} \mathrm{u}^{1,2} \cdot$ Jing Wang ${ }^{1} \cdot \mathrm{Bin} \mathrm{Wu}^{4} \cdot \mathrm{Xiaodong} \operatorname{Tian}^{3} \cdot$ \\ Yan $\mathrm{Li}^{4} \cdot$ Ying $\mathrm{He}^{2} \cdot \mathrm{Fan}_{\mathrm{Li}^{2}} \cdot \mathrm{Kai} \mathrm{Nie}^{2} \cdot$ Songtao $\mathrm{Xu}^{2} \cdot$ Bin Wang ${ }^{1} \cdot$ Huanyu Wang ${ }^{2}$ (D) Xiaoqing $\mathrm{Lu}^{1}$ (1) \\ Guodong Liang ${ }^{2}$ (i)
}

Received: 17 November 2020 / Accepted: 25 March 2021 / Published online: 31 May 2021

(c) Wuhan Institute of Virology, CAS 2021

\begin{abstract}
We previously isolated a new species of the genus Phlebovirus from wild sandflies collected from Wuxiang County in central China, which named the Wuxiang virus (WUXV). In this study, we re-isolated the WUXV from wild sandflies collected from two villages in Yangquan County, China in 2019. Four virus isolates that caused cytopathic effects in BHK21 cells were successfully isolated from sandfly specimens collected from chicken pens and sheep pens. Phylogenetic analyses of the $L, M$ and $S$ gene segments of the viruses revealed that the four virus strains represented the previously isolated WUXV. The minimum infection rate (MIR) of the virus isolated from the sheep pen was 3.21, and the MIR of the virus isolated from the chicken pen was 3.45. The positive rates of Wuxiang virus neutralizing antibodies in serum samples of local healthy people and domestic chickens were $8.7 \%$ (4/46) and 100\% (4/4), respectively, suggesting that Wuxiang virus can infect human and animal. In view of the fact that Wuxiang virus is infectious to humans and animals and has a relatively wide geographical distribution in China, it is of great public health significance to strengthen the investigation and study on the infection status of Wuxiang virus in humans and animals.
\end{abstract}

Keywords Sandfly $\cdot$ Phlebovirus $\cdot$ Wuxiang virus (WUXV)

Qinyan Wang, Shihong Fu, Jingxia Cheng have Contributed equally to this work

Supplementary Information The online version contains supplementary material available at https://doi.org/10.1007/s12250021-00398-4.

Guodong Liang

gdliang@hotmail.com

$\triangle$ Xiaoqing $\mathrm{Lu}$

Luxq532@126.com

$\square$ Huanyu Wang

wanghy@ivdc.chinacdc.cn

1 Qingdao University, Qingdao 266071, China

2 State Key Laboratory of Infectious Disease Prevention and Control, National Institute for Viral Disease Control and Prevention, Chinese Center for Disease Control and Prevention, Beijing 102206, China

3 Shanxi Province Center for Disease Control and Prevention, Taiyuan 030001, China

4 Yangquan Center for Disease Control and Prevention, Yangquan 045000, China

\section{Introduction}

Phleboviruses belong to the Phenuiviridae family of the order Bunyavirales (Maes et al. 2019). In March 2020, the International Committee on Taxonomy of Viruses (ICTV) released the latest Phenuiviridae classification guidelines. The Phenuiviridae family includes 60 different virus types, such as the sandfly-borne Toscana virus (TOSV), Toros virus (TORV), the mosquito-borne Rift Valley fever virus, and sandfly fever Naples virus. According to the latest ICTV classification guidelines, the tick-borne severe fever with thrombocytopenia syndrome virus (SFTSV) and Heartland virus (HLV) are not included in the Phlebovirus genus (Kuhn et al. 2020; Walker et al. 2020). The number of newly identified Phleboviruses has increased drastically over the past few years, suggesting that Phleboviruses are abundant in nature.

In 2018, we isolated a sandfly-borne Wuxiang virus (WUXV) from a sandfly in China; we termed this isolate SXWX1813-2 virus (Wang et al. 2020). SXWX1813-2 virus inoculating in BHK-21 cells led to significant 
cytotoxicity. In newborn mice, the virus caused morbidity and death. Whole-genome sequencing of this new WUXV isolate revealed three gene segments ( $L$ gene, $M$ gene, and $S$ gene). Molecular genetic evolution analyses of the viral genome indicated that the WUXV differs phylogenetically from other Phleboviruses, forming an independent phylogenetic branch (Wang et al. 2020).

The SXWX1813-2 virus is the first Phlebovirus isolated from a sandfly in East Asia (Depaquit et al. 2010; Liang et al. 2018; Wang et al. 2020). However, it remains unclear whether there are sandfly-borne viruses in nature in other regions. In 2019, we isolated viruses from sandflies collected from Yangquan County, and identified four isolates that can cause cytopathic effects (CPE) in BHK-21 cells. Molecular analyses showed that all four isolates belonged to the WUXV. Herein, we report the re-isolation of a new Phlebovirus from a sandfly collected in a natural environment in China. The results also showed that local healthy people and chicken serum samples were positive for neutralizing antibody of Wuxiang virus.

\section{Materials and Methods}

\section{Sample Collection}

Wild sandfly specimens were collected from chicken, sheep, and cattle pens used to breed blood-sucking insects. Specimens were collected using an insect collector (MM200; Guangzhou Changsheng Chemical Co., Ltd., Guangdong, China). The specimen collectors were placed at each sampling point from $6 \mathrm{PM}$ to $7 \mathrm{AM}$. The collected insects were placed in a low-temperature refrigerator for 20 min and then kept on ice during morphological identification and isolation of blood-sucking insects. Sandfly specimens were divided based on the collection environment and stored in liquid nitrogen until further testing (Fu et al. 2017; Song et al. 2017; Wang et al. 2020).

Whole blood of local healthy people and chicken were also collected at place where the sandfly specimens were collected, and the sera were obtained after centrifugation at $2000 \mathrm{rpm}$ for $20 \mathrm{~min}$. Sera samples were transported to the laboratory with ice platoons, stored in a low temperature refrigerator for testing.

\section{Cells}

The golden hamster kidney cells BHK-21 were maintained in $90 \%$ Eagle's medium (made in-house) supplemented with 7\% fetal bovine serum (FBS; Invitrogen, Carlsbad, CA, USA), $1 \%$ penicillin and streptomycin $(100 \mathrm{U} / \mathrm{mL})$, $1 \%$ glutamine $(30 \mathrm{~g} / \mathrm{L})$, and $1 \% \mathrm{NaHCO}_{3}$. The Aedes albopictus egg cells C6/36 were cultured in $89 \%$ RMPI
1640 (Invitrogen) supplemented with 10\% FBS (Invitrogen) and $1 \%$ penicillin and streptomycin $(100 \mathrm{U} / \mathrm{mL})$. BHK-21 and C6/36 cells were maintained in a $5 \% \mathrm{CO}_{2}$ humified atmosphere. BHK-21 cells were cultured at 37 ${ }^{\circ} \mathrm{C}$, whereas $\mathrm{C} 6 / 36$ cells were kept at $28{ }^{\circ} \mathrm{C}$ (Fu et al. 2017; Song et al. 2017; Wang et al. 2020).

\section{Virus Isolation}

Sandfly specimens were pooled into 23 groups with 50-100 sandflies in each group. Specimens were placed in a glass grinder and homogenized in grinding solution $(93 \%$ Eagle's medium, 5\% penicillin and streptomycin [100 $\mathrm{U} / \mathrm{mL}], 1 \%$ glutamine $[30 \mathrm{~g} / \mathrm{L}]$, and $1 \% \mathrm{NaHCO}_{3}$ ) at $4{ }^{\circ} \mathrm{C}$. Samples were centrifuged $\left(4^{\circ} \mathrm{C}, 12,000 \mathrm{rpm}, 30 \mathrm{~min}\right)$, and $100 \mu \mathrm{L}$ of the supernatant was inoculated into BHK-21 cell and $\mathrm{C} 6 / 36$ cells seeded at a density of $80 \%$ in 24-well plates (Corning Inc., New York, NY, USA). After inoculation, BHK-21 and C6/36 cells were cultured in a 5\% $\mathrm{CO}_{2}$ atmosphere at $37{ }^{\circ} \mathrm{C}$ and $28{ }^{\circ} \mathrm{C}$, respectively. CPE was monitored under a microscope every $12 \mathrm{~h}$. When CPE became evident, viral samples were collected and stored at $-80{ }^{\circ} \mathrm{C}$ until further characterization. Specimens were blindly passaged three times; cells without CPE were discarded (Fu et al. 2017; Song et al. 2017).

\section{Viral RNA Extraction and cDNA Synthesis}

Viral total RNA was extracted using a Viral RNA Mini Kit (QIAamp; Qiagen, Valencia, CA, USA) following the manufacturer's instructions. Total RNA was extracted from sandfly specimens after homogenization, as well as from the supernatant of infected BHK-21 and C6/36 cells. The extracted RNA was immediately placed in a $65{ }^{\circ} \mathrm{C}$ water bath for $10 \mathrm{~min}$ and then transferred on ice for $2 \mathrm{~min}$. RNA samples $(32 \mu \mathrm{L})$ were used for first-strand cDNA synthesis (Ready-To-Go You-Prime First-Strand Beads; GE Healthcare, Little Chalfont, UK). The reaction also included $1 \mu \mathrm{L}$ of random primers (TaKaRa, Shiga, Japan) and was incubated at $37{ }^{\circ} \mathrm{C}$ for $1 \mathrm{~h}$. The resulting cDNA was used immediately, or stored at $-40{ }^{\circ} \mathrm{C}$ until further use (Feng et al. 2017; Ren et al. 2017; Wang et al. 2020).

\section{Gene Amplification and Sequencing}

Viral genes were amplified by polymerase chain reaction (PCR), which included cDNA template, GoTaq ${ }^{\circledR}$ Green Master Mix $2 \times$ (Promega, Madison, WI, USA), and 10 $\mu \mathrm{mol} / \mathrm{L}$ of each primer (total reaction volume of $25 \mu \mathrm{L}$ ). Amplification products were resolved by $1 \%$ agarose gel electrophoresis and subjected to sequencing (Feng et al. 2017; Ren et al. 2017; Wang et al. 2020). The sequences of the primers used in this study were previously described 
(Wang et al. 2020). We used nine primer pairs for WUXV $M$ genes and six for WUXV $S$ genes. Four $M$ gene amplification primers and two $S$ gene amplification primers did not yield amplification products. Therefore, amplification primers were redesigned for genes that could not be amplified. Specifically, we designed five $M$ gene amplification primer pairs and two $S$ gene amplification primer pairs. We designed eleven $L$ gene primer pairs for PCR amplification. By using these primers, we obtained amplification products for all viral genes. The sequencing primers used in this study are listed in Supplementary Table S1.

\section{Nucleotide Sequence Analysis}

BLAST analyses were conducted using the viral gene nucleotide sequences. SeqMan software (DNAStar, Madison, WI, USA) was used for sequence splicing and quality analyses, and BioEdit (version 7.0; http://www.mbio.ncsu. edu/BioEdit/bioedit.html) was used for multiple sequence alignment. System evolution analysis was conducted using MEGA 6.0 software (https://www.megasoftware.net/) and the neighbor-joining method (bootstrap value of 1000). MegAlign was used for homology analysis of nucleotide and amino acid sequences (DNAStar) (Feng et al. 2017, 2019; Song et al. 2017; Wang et al. 2020). Viral gene sequences were obtained from GenBank (NCBI, Bethesda, ND, USA) for comparison.

\section{Molecular Identification of Sandflies}

DNA extracted from pools of sandflies positive for WUXV was used for mitochondrial cytochrome C oxidase I (COI) amplification (Folmer et al. 1994) and sequencing. The sequences of the upstream COI primer (LCO1490; ggtcaacaaatcataaagatattgg) and downstream COI primer (HC02198; taaacttcagggtgaccaaaaaatca) were used for BLAST analyses of GenBank data to determine the sandfly species (Folmer et al. 1994; Wang et al. 2020).

\section{Minimum Infection Rate (MIR)}

The infection rate of a pool of positive specimens was calculated using the following formula: pool infection rate $=$ number of positive specimens $\div$ total number of specimens $\times 100 \%$. Assuming that each positive pool contained only one infected sandfly, we calculated the MIR of 1000 sandflies as follows: number of positive specimen pools (number of infected sandflies) $\div$ total number of sandflies $\times 1000$ (Feng et al. 2012).

\section{Detection of Neutralizing Antibody}

BHK-21 cells were introduced into a 6-well plate and grown into monolayer cells the next day, with a coverage rate of $80 \%$. The viral solution was diluted with serum-free Eagle's solution to a concentration of $200 \mathrm{PFU} / 0.1 \mathrm{~mL}$. Serum samples were placed in $56{ }^{\circ} \mathrm{C}$ water bath for $30 \mathrm{~min}$ to inactivate complement. Serum samples were diluted with serum-free Eagle's solution at 1:5. Set back titration of $100 \mathrm{PFU}, 50 \mathrm{PFU}, 10 \mathrm{PFU}$. The diluted virus solution was mixed with serum in equal proportion and incubated in $37{ }^{\circ} \mathrm{C}$ incubator for $1 \mathrm{~h} .0 .1 \mathrm{~mL}$ of the serum and virus mixture was added to each well, and the virus back titration was added to the wells at the same time for 2 wells per titer, and incubated at $37{ }^{\circ} \mathrm{C}$ for $1 \mathrm{~h}$. Then $4 \mathrm{~mL}$ methylcellulose was added to cover cells per well, and the cells were cultured in incubator at $37{ }^{\circ} \mathrm{C}$. Cytopathy of cells was observed daily. When the plaques were obvious, crystal violet staining was performed, and plaques were observed and counted. The plaque reduction neutralization test (PRNT50) was used as the standard, when the corresponding plaque number was less than that of the standard, and the dilution ratio of serum samples was considered as the neutralization titer (Cao et al. 2016).

\section{Results}

\section{Sandfly Sample Collection}

Sandfly specimens were collected in June 2019 from sheep, chicken, and cattle pens in two villages in Yangquan County, Shanxi Province. A total of 1535 sandflies were collected from the two villages (1047 and 488 from the first and second villages, respectively). In total, 935 of these sandflies were collected from a sheep pen, 290 from a chicken pen, and 310 from a cattle pen (Table 1).

\section{Virus Isolation}

The collected sandflies were pooled into 23 groups before homogenization, and the supernatant of each pool was inoculated into BHK-21 and C6/36 cells after homogenization. SXYQ1916 sandfly specimens were also inoculated into BHK-21 cells, and CPE was observed after 3 days of inoculation. Notably, cells exhibited significant shrinkage and shedding (Fig. 1). Sandfly specimens were inoculated into BHK-21 cells, and continued culture and passaging of cells, then four virus strains were isolated (Table 2). In contrast, the inoculation of sandfly supernatants into C6/36 cells did not lead to CPE. And we obtained nothing after PCR amplification using C6/36 cell supernatants and WUXV-specific primers. 
Table 1 Collection sites of sandfly specimens in Yangquan County, Shanxi Province in 2019.

\begin{tabular}{lllll}
\hline Collection site & \multicolumn{2}{l}{ Breeding places } & Total \\
\cline { 2 - 4 } & Sheep pen & Chicken pen & Cattle pen & \\
\hline 1 & 554 & 183 & 310 & 1047 \\
2 & 381 & 107 & $/$ & 488 \\
Total & 935 & 290 & 310 & 1535 \\
\hline
\end{tabular}

"/" represents the missing cattle pen.

"1" indicates the first sampling village (east longitude $113^{\circ} 37^{\prime} 12^{\prime \prime}$, north latitude $37^{\circ} 46^{\prime} 48^{\prime \prime}$ ). There were more than 100 chickens in the chicken pen, 170 sheep in the sheep pen, and 18 cattle in the cattle pen. The distance between the three pens was less than $1000 \mathrm{~m}$. "2" indicates the second sampling village (east longitude $113^{\circ} 38^{\prime} 24^{\prime \prime}$, north latitude $37^{\circ} 45^{\prime}$ ). There were 70 sheep in the sheep pen and 10 chickens in the chicken pen. Sheep and chicken pens were in the courtyard of the residents, which had two dogs in the house. The two pens were approximately $2 \mathrm{~km}$ apart, and the two villages were about $4 \mathrm{~km}$ apart.
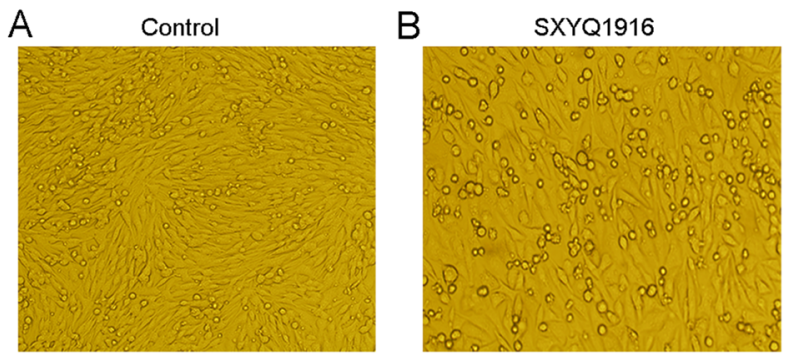

Fig. $1 \mathrm{CPE}$ of the WUXV isolate SXYQ1916 in BHK-21 cells. A BHK-21 cells as negative control were cultured for 3 days. B BHK21 cells were also cultured for 3 days after the inoculation of WUXV isolate SXYQ1916. Culture in the presence of the SXYQ1916 virus led to a decrease in the number of adherent BHK-21 cells, and profound cell rounding and detachment. Magnification, $\times 100$.

\section{The MIR of WUXV}

By dividing all 1535 sandflies into 23 pools and inoculating them into BHK-21 cells, we obtained four virus isolates that caused CPE in BHK-21 cells. The infection rate of these viral pools was $17.39 \%$ (4/23), and the MIR was 2.61 $(4 / 1535 \times 1000)$. Among the 14 pools of sandfly specimens collected from the sheep pen, three contained the WUXV. The infection rate of WUXV pools isolated from the sheep pen was $21.43 \%$ (3/14), and the MIR was 3.21 (3/ $935 \times 1000)$. The infection rate of viral pools isolated from the chicken pen was $20.00 \%$ (1/5), and the MIR of the WUXV virus was $3.45(1 / 290 \times 1000)$. In addition, 310 sandflies were collected from the cattle pen and divided into four pools. We could not isolate a virus from any of these viral pools, and we did not detect any of the WUXV genes. The infection rates of the different WUXV isolates are shown in Table 3.

\section{Homology in the Gene Sequences of Virus Isolates}

The sequences of the coding regions of the virus WUXV $S$ and $M$ genes were determined for all four virus isolates. Interestingly, the two genes were of the same length in all four virus isolates. The coding sequence of the $S$ gene was 1611 base pairs (bp), whereas the coding sequence of the $M$ gene was $4089 \mathrm{bp}$, similar to the length of the respective genes of the WUXV (SXWX1813-2). The $L$ gene of the SXYQ1927-2 virus isolate was amplified, and the nucleotide sequence was determined and analyzed. The length of the nucleotide and the amino acid sequences of the encoding region of the $L$ gene are 6273 nt and 2090 aa, respectively. BLAST analyses revealed that the sequences of the $M$ gene exhibited similarities of $96.8 \%-99.5 \%$ among the four strains. Similarly, the amino acid sequences of the NS and N proteins encoded by the $S$ gene were 98.2\%-99.6\% similar among the four strains (Supplementary Tables S2-S4). The results of the homology analysis of the newly isolated virus (SXYQ1916) and other Phleboviruses are shown in Table 4. We found 96.7\%, $97.1 \%$, and $98.0 \%$ sequence similarity in genes $M, N S$, and $N$ between the newly isolated strain SXYQ1916 and a

Table 2 Isolation of Wuxiang virus in Yangquan County, Shanxi Province in 2019.

\begin{tabular}{|c|c|c|c|c|c|c|c|c|c|c|}
\hline \multirow{3}{*}{$\begin{array}{l}\text { Strain } \\
\text { number }\end{array}$} & \multirow{3}{*}{$\begin{array}{l}\text { Collection } \\
\text { site }\end{array}$} & \multirow{3}{*}{$\begin{array}{l}\text { Breeding } \\
\text { places }\end{array}$} & \multirow{3}{*}{$\begin{array}{l}\text { Number of } \\
\text { Phlebotomus } \\
\text { chinensiss }\end{array}$} & \multicolumn{7}{|c|}{ CPE/ Gene amplification } \\
\hline & & & & \multirow[t]{2}{*}{ BHK-21 cell } & \multicolumn{3}{|l|}{ WUXV } & \multirow[t]{2}{*}{ C6/36 cell } & \multicolumn{2}{|c|}{ WUXV } \\
\hline & & & & & $\mathrm{L}$ & M & $S$ & & M & $\mathrm{S}$ \\
\hline SXYQ1931 & 1 & Sheep pen & 60 & + & l & MW192757 & MW192753 & - & - & - \\
\hline SXYQ1916 & 2 & Sheep pen & 49 & + & l & MW192754 & MW192750 & - & - & - \\
\hline SXYQ1930 & 2 & Sheep pen & 74 & + & l & MW192756 & MW192752 & - & - & - \\
\hline SXYQ1927-2 & 2 & Chicken pen & 54 & + & MW368897 & MW192755 & MW192751 & - & - & - \\
\hline
\end{tabular}

Numbers indicate the collection location. Numbers 1 and 2 indicate the first and second sampling villages, respectively; " + " means that the experimental result is positive; "-" means that the experimental result is negative; "/" means that the experiment was not performed. 
Table 3 Infection rate of Sandfly-borne virus.

\begin{tabular}{llcll}
\hline Breeding places & Number of sandflies & Pool & Infection rate of pools $(\%)$ & MIR (/1000) \\
\hline Chicken pen & 290 & 5 & $20.00(1 / 5)$ & $3.45(1 / 290)$ \\
Sheep pen & 935 & 14 & $21.43(3 / 14)$ & $3.21(3 / 935)$ \\
Cattle pen & 310 & 4 & $0.00(0 / 4)$ & $0.00(0 / 310)$ \\
\hline
\end{tabular}

WUXV strain (SXWX1813-2) previously isolated in China (Wang et al. 2020); the respective amino acid sequence similarities were $97.6 \%, 97.7 \%$, and $99.6 \%$. Moreover, comparisons between SXYQ1916 and a TORV strain (213/ Turkey/2012) isolated from Turkey sandfly specimens revealed $72.0 \%$ nucleotide ( $75.1 \%$ amino acid) sequence similarity in the M segment, $75.4 \%$ (85.1\%) similarity of the NS protein in the S segment, and $82.2 \%$ (96.4\%) similarity of the $\mathrm{N}$ protein in the $\mathrm{S}$ segment (Table 4). These results suggested that the virus isolated from sandflies in Yangquan County is the same with the WUXV strain previously isolated from sandflies in China.

\section{Phylogenetic Analysis of Viral Genes}

We performed phylogenetic analysis based on the genetic sequences of the four virus strains isolated from sandfly specimens in Yangquan County in 2019, and those of 60 sandfly viruses reclassified by ICTV in 2020. We found that the four virus strains isolated in this study belonged to the same evolutionary branch as the previously isolated WUXV strain (SXWX1813-2). On the basis of the sequences of the $S$ (including the NS and N coding sequences), $M$ and $L$ gene, these viruses belonged to the same evolutionary population as the TORV isolated from Turkey sandflies in 2012-2013 (Fig. 2).

\section{Identification of Sandfly Species}

To identify the species of the collected sandflies, we used PCR to amplify the COI gene. We found that all four pools of sandflies used to isolate the viruses belonged to the species Phlebotomus chinensis (Table 2).

\section{Detection of Neutralizing Antibody of WUXV}

In this study, 46 serum samples of healthy people were collected. The neutralizing antibody level of WUXV in serum samples was detected by plaque neutralization test (when the ratio of WUXV and neutralizing antibody in serum was 1:10, the sample was positive). The results showed that $8.70 \%(4 / 46)$ of the serum samples were positive in local heathy people. The neutralization titers of WX14, WX44 positive specimens were 1:10, WX28 and WX34 positive specimens were 1:20. The serum neutralizing antibodies of four chickens were all positive with titers ranging from 1:10 to $1: 160$. The results of neutralizing antibody test were shown in Table 5 .

Table 4 Homology analysis of the newly isolated virus (SXYQ1916) and other Phleboviruses.

\begin{tabular}{|c|c|c|c|c|c|c|}
\hline \multirow[t]{3}{*}{ Virus strains } & \multirow{2}{*}{\multicolumn{2}{|c|}{$\frac{\mathrm{M} \text { segment }}{\mathrm{GP}}$}} & \multicolumn{4}{|l|}{ S segment } \\
\hline & & & \multicolumn{2}{|l|}{ NS } & \multicolumn{2}{|l|}{$\mathrm{N}$} \\
\hline & nt $(\%)$ & aa $(\%)$ & nt $(\%)$ & aa $(\%)$ & nt $(\%)$ & aa $(\%)$ \\
\hline SXYQ1916 & 4089 & 1362 & 783 & 260 & 741 & 246 \\
\hline SXWX1813-2 & 4089(96.7) & 1362(97.6) & 783(97.1) & $260(97.7)$ & $741(98.0)$ & 246(99.6) \\
\hline TORV(213/Turkey/2012) & $4080(72.0)$ & $1359(75.1)$ & $783(75.4)$ & $260(85.1)$ & $741(82.2)$ & $246(96.4)$ \\
\hline TORV(292/Turkey/2012) & $4081(72.0)$ & $1359(75.1)$ & $783(75.2)$ & $260(85.1)$ & $741(81.9)$ & $246(96.0)$ \\
\hline CFUV(Pa Ar 814/Greece/1981) & $4080(71.3)$ & $1359(75.7)$ & $783(74.5)$ & $260(84.3)$ & $741(81.9)$ & 246(96.4) \\
\hline SFSV(Ethiopia-2011/Ethiopia / 2011) & $4026(62.6)$ & $1341(57.1)$ & I & l & $741(74.4)$ & $246(84.2)$ \\
\hline SFSV(Sabin/Italy/1943) & l & l & $783(53.3)$ & $260(63.6)$ & $741(75.3)$ & $246(83.8)$ \\
\hline DASHV(131/Iran/2011) & $4029(65.2)$ & $1342(58.6)$ & $786(58.1)$ & $261(61.7)$ & $741(76.5)$ & $246(85.0)$ \\
\hline RVFV(ZH-548/Egypt/1977) & $3594(36.0)$ & 1197(39.9) & $798(15.5)$ & $265(24.1)$ & $738(55.4)$ & $245(52.8)$ \\
\hline
\end{tabular}

"/" indicates that the sequence was not available in the GenBank database. 
Fig. 2 Phylogenetic analyses of the genetic sequences of the four virus strains isolated from sandflies collected in Yangquan in 2019. A Phylogenetic analysis of isolates SXYQ1916, SXYQ1927-2, SXYQ1930, SXYQ1931 (black dots) based on the $M$ gene sequence. B Phylogenetic analysis of isolates SXYQ1916,

SXYQ1927-2, SXYQ1930, SXYQ1931 based on the $S$ gene sequence (black dots).

C Phylogenetic analysis of isolates SXYQ1927-2 (black dots) based on the $L$ gene sequence. The phylogenetic analysis was conducted using MEGA 6.0 software and the neighbor-joining method (bootstrap value of 1000). Note For phylogenetic comparison, we used the gene sequences of Phleboviruses from the ICTV 2020 guidelines; “/” indicates that the sequence was not available in the GenBank database.
A

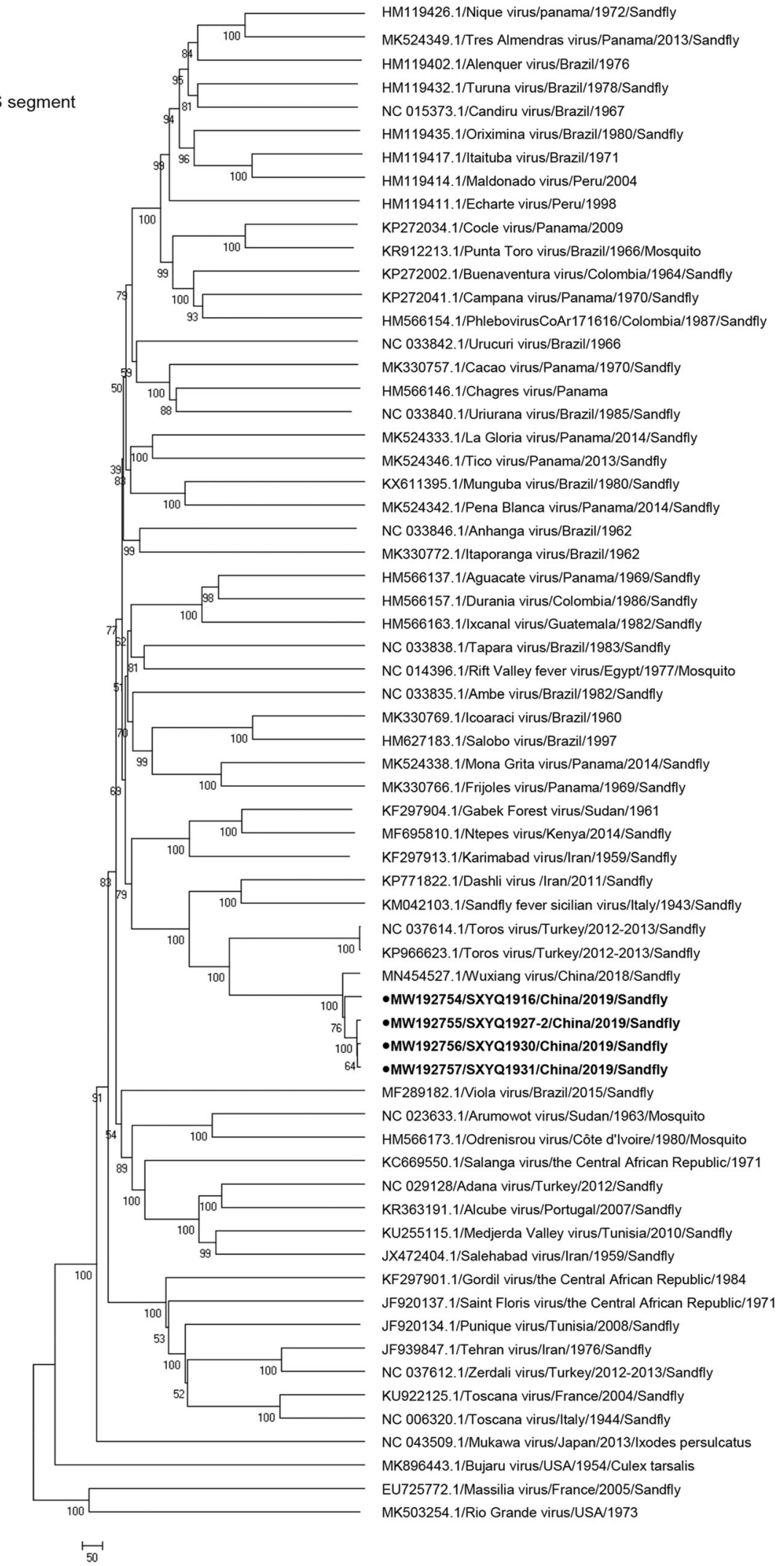


Fig. 2 continued
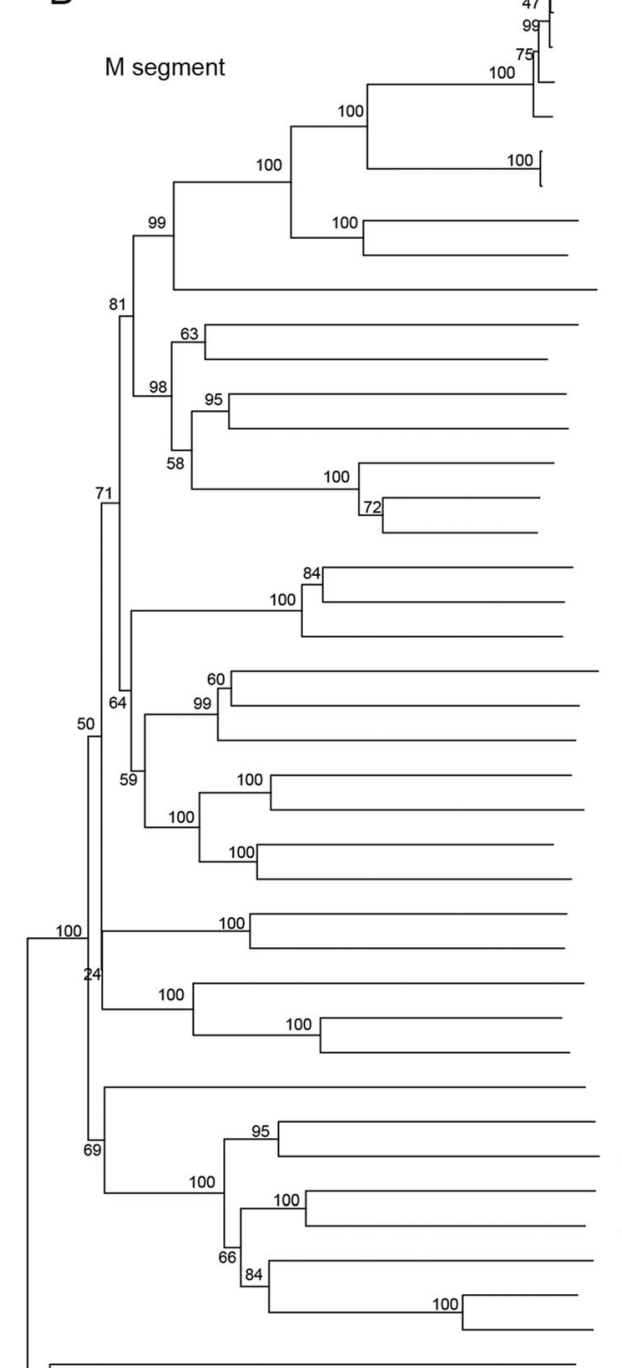

B

B

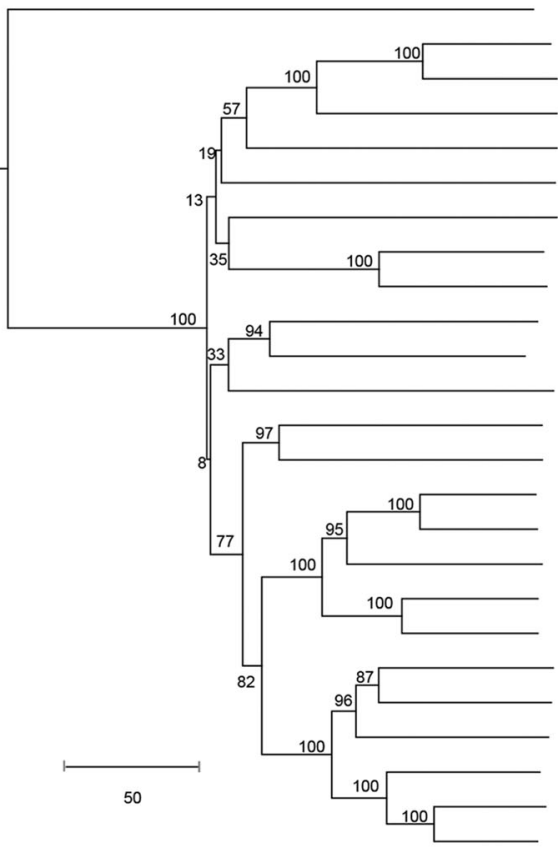

-MW192751/SXYQ1927-2/China/2019/Sandfly •MW192753/SXYQ1931/China/2019/Sandfly •MW192725/SXYQ1930/China/2019/Sandfly •MW192750/SXYQ1916/China/2019/Sandfly MN454528.1Muxiang virus/China/2018/Sandfly NC_037615.1/Toros virus/Turkey/2012-2013/Sandfly KP966624.1/Toros virus/Turkey/2012-2013/Sandfly KP771823.1/Dashli virus//ran/2011/Sandfly EF201822.1/Sandfly fever sicilian virus/Italy/1943/Sandfly NC 014395.1/Rift Valley fever virus/Egypt/1977/Mosquito NC 033845.1/Ambe virus/Brazil/1982/Sandfly NC 033839.1/Tapara virus/Brazil/1983/Sandfly MK524339.1/Mona Grita virus/ Panama/2014/Sandfly HM627184.1/Salobo virus/Brazil/1997 HM566156.1/Durania virus/Colombia/1986/Sandfly HM566139.1/Aguacate virus/Panama/1969/Sandfly HM566161.1/lxcanal virus/Guatemala/1982/Sandfly HM119415.1/Maldonado virus/Peru/2004 HM119433.1/Turuna virus/Brazil/1978/Sandfly MK524350.1/Tres Almendras virus/Panama/2013/Sandfly NC 033850.1/Uriurana virus/ Brazil/1985/Sandfly NC 033843.1/Urucuri virus/Brazil/1966 HM566187.1/Phlebovirus GGP-2011a/Venezuela MK524334.1/La Gloria virus/Panama/2014/Sandfly MK524347.1/Tico virus/Panama/2013/Sandfly KX611396.1/Munguba virus/Brazil/1980/Sandfly MK524343.1/Pena Blanca virus/Panama/2014/Sandfly NC 033837.1/Anhanga virus/Brazil/1962 MK503255.1/Rio Grande virus/USA/1973 NC 023634.1/Arumowot virus/Sudan/1963/Mosquito NC 029129.1/Adana virus/Turkey/2012/Sandfly KU297253.1/Medjerda Valley virus/Tunisia/2010/Sandfly KC669551.1/Salanga virus/the Central African Republic/1971 KF297902.1/Gordil virus/the Central African Republic/1984 JF920138.1/Saint Floris virus/the Central African Republic/1971 EU725773.1/Massilia virus/France/2005/Sandfly JF920135.1/Punique virus/Tunisia/2008/Sandfly NC 037613.1/Zerdali virus/Turkey/2012-2013/Sandfly KU922126.1/Toscana virus/France/2004/Sandfly NC 006318.1/Toscana virus/taly/1944/Sandfly MK896442.1/Bujaru virus/USA/1954/Culex tarsalis KF297905.1/Gabek Fores tvirus/Sudan/1961 MF695811.1/Ntepes virus/Kenya/2014/Sandfly KF297914.1/Karimabad virus/lran/1959/Sandfly NC 043511.1/Mukawa virus/Japan/2013/lxodes persulcatus MK330773.1/Itaporanga virus/Brazil/1962 HM566175.1/Odrenisrou virus/Côte d'Ivoire/1980/Mosquito KR363192.1/Alcube virus/Portugal/2007/Sandfly JX472405.1/Salehabad virus/lran/1959/Sandfly MK330770.1//coaraci virus/Brazil/1960 MK330767.1/Frijoles virus/Panama/1969/Sandfly JF939848.1/Tehran virus//ran/1976/Sandfly MK330758.1/Cacao virus/Panama/1970/Sandfly HM566148.1/Chagres virus/Panama KP272035.1/Cocle virus/Panama/2009 KR912211.1/Punta Toro virus/Brazil/1966/Mosquito HM566153.1/PhlebovirusCoAr171616/Colombia/1987/Sandfly KP272003.1/Buenaventura virus/Colombia/1964/Sandfly KP272042.1/Campana virus/Panama/1970/Sandfly HM119403.1/Alenquer virus/Brazil/1976 HM119427.1/Nique virus/panama/1972/Sandfly HM119412.1/Echarte virus/Peru/1998 HM119436.2/Oriximina virus/Brazil/1980/Sandfly HM119418.2/ttaituba virus/Brazil/1971 NC 015375.1/Candiru virus/Brazil/1967 
Table 5 Detection of neutralizing antibody against WUXV.

\begin{tabular}{lllllllll}
\hline Number & Gender & Age & \multicolumn{2}{l}{ Livestock raised } & \multirow{2}{*}{ Neutrlization test (Serum dilution) } & WUXV gene amplification \\
\cline { 3 - 6 } & & & Chicken & Sheep & Dog & & \\
\hline WX14 & Female & 66 & 10 & - & 1 & $+(1: 10)$ & - \\
WX28 & Male & 68 & & & & $+(1: 20)$ & - \\
WX34 & Male & 61 & - & - & 1 & $+(1: 20)$ & - \\
WX44 & Male & 59 & - & - & 1 & $+(1: 10)$ & - \\
\hline
\end{tabular}

Table 5 shows the background information of healthy people and chickens with neutralizing antibody positive in serum specimens. The blood donors of WX14 and WX28 came from the same family, which raised 10 chickens and $1 \mathrm{dog}$. Other positive individual families raised only one dog but not sheep, chickens and other livestock and poultry. "-" means that the experimental result is negative.

\section{Discussion}

We have previously isolated the sandfly-borne virus WUXV from wild sandflies collected from Wuxiang County, Shanxi Province, China (Wang et al. 2020). In this study, we re-isolated WUXV from wild sandflies collected from Yangquan County, Shanxi Province, China. Molecular phylogenetic analyses revealed that these virus isolates represented different geographical isolates of WUXV viruses, suggesting that the WUXV can also be found in wild sandflies outside Wuxiang County.

Yangquan County (east longitude $112^{\circ} 5^{\prime}-114^{\circ} 4^{\prime}$, north latitude $37^{\circ} 40^{\prime}-38^{\circ} 31^{\prime}$ ) is located in Shanxi Province in central China, on the west side of the central Taihang Mountains with an average elevation of 700-1700 m. Yangquan has a warm, arid continental climate characterized by limited rainfall, and an ecological environment favoring the growth and reproduction of blood-sucking insects, such as sandflies and mosquitoes. In this study, we collected sandfly specimens from two regions of Yangquan County. One sampling point was located $9 \mathrm{~km}$ southeast of the center of Yangquan town, and the other was $13 \mathrm{~km}$ from the town; the distance between the two specimen collection points was approximately $4 \mathrm{~km}$. The farmland around the two villages was mainly planted with corn and sorghum. Specimens were collected from sheep and chicken pens at each of the two villages. From the first village, we also collected samples from a cattle pen. All specimens were collected on June 11, 2019. Specimen collectors were placed at two collection points at the same time, and each of the sheep and chicken pens had one collector. Collectors were left overnight, and a total of 1535 sandflies were collected from both villages. Most of the sandflies were collected from the sheep pens $(n=935)$; only 290 samples were from the chicken pens. Three (SXYQ1916, SXYQ1930, SXYQ1927-2) of the four virus isolates in this study were derived from the sheep pen, and one isolate (SXYQ1931) came from the chicken pen. These results demonstrate that sandflies were abundant in Yangquan County in June 2019.

Four different virus strains were isolated from wild sandflies collected from Yangquan County. The infection rate of these virus isolates differed significantly. The infection rate of the WUXV pool from the sheep pen was $21.43 \%$, and the MIR was 3.21; the infection rate of the viral pool from the chicken pen was $20.00 \%$, and the MIR was 3.45. In previous studies conducted in coastal countries in the Mediterranean region, the MIR of the TOSV isolated from Turkey sandflies was 2.2 (Calzolari et al. 2018), the MIR of Ntepes virus isolated from Kenyan sandflies was 0.26 (Tchouassi et al. 2019), and the MIR of Zerdali virus isolated from Turkey sandflies was 0.35 (Alkan et al. 2016). TORV was isolated from sandflies collected from Turkey in 2012, and its MIR was 0.26 (Alkan et al. 2016). Although phylogenetic analyses revealed that the WUXV isolated in Yangquan County, China, and the TORV isolated from Turkey were closely related, the MIR of the WUXV was significantly higher than that of the TORV (2.61 vs. 0.26). The pooled infection rate and MIR of WUXV from local sandflies were significantly higher than those of viruses isolated from Mediterranean region sandflies. The biological significance and pathogenicity of the virus carried by sandflies requires further investigation. In this study, the positive rates of Wuxiang virus neutralizing antibodies detected in the serum samples of local healthy people and domestic chickens were 8.4\% (4/46) and 100\% (4/4), respectively. Although the number of serum specimens collected in this study is limited, and only serum specimen from one animal (chicken)was collected, the above results suggest Wuxiang virus can infect humans and domestic chickens. Therefore, in the future, it is necessary to investigate the infection status of Wuxiang virus in local humans and animals to clarify the harm of the virus to public health.

The revised guidelines from ICTV meeting in 2020 recommended the addition of 53 new Phleboviruses (Kuhn et al. 2020). The previous ICTV classification guidelines 
included only 10 Phlebovirus species (Abudurexiti et al. 2019), including the SFTSV isolated in China (Yu et al. 2011) and the Hartland virus isolated in the USA (Shen et al. 2018). These two viruses are not classified as Phleboviruses according to the new ICTV guidelines, although 53 newly identified Phleboviruses were added. In this study, we conducted a molecular evolution analysis of the WUXV isolated in China in 2018 (Wang et al. 2020), and the newly identified Phleboviruses included in the revised ICTV classification guidelines. Among the new Phlebovirus species, 37 were isolated in the Americas (16 in North America and 21 in South America), 10 were isolated in Africa (1 in West Africa, 1 in East Africa, 3 in Central Africa, and 5 in North Africa), 8 were first isolated in Asia ( 1 in East Asia and 7 in West Asia), and 5 were from Europe (5 from Western Europe). A significant number of these Phleboviruses ( $n=37$ strains) uses sandflies as their transmission vector; 5 viruses are transmitted through mosquitoes, and one via ticks; the transmission vector is unknown for the remaining 17 viruses (Fig. 2). Here, we analyzed the $M$ and $S$ gene sequences of the four WUXV strains isolated from Yangquan sandflies (Fig. 2), and found that these isolates belonged to the same evolutionary branch as the TORV (Alkan et al. 2016); this suggested that WUXV may have derived from the TORV isolated from Turkey sandflies in 2012 (Alkan et al. 2016).

In this study, we re-isolated the WUXV from wild sandflies collected from Yangquan County, a different region from where the WUXV was originally isolated. These findings suggest that the WUXV has a relatively wide geographical distribution range. In addition, the neutralizing antibody of Wuxiang virus was detected in both human and chicken serum specimens (Table 5), suggesting that the local people and domestic chickens were infected with Wuxiang virus. Therefore, it is of great significance to strengthen the seroepidemiological investigation of Wuxiang virus in local humans and animals.

Acknowledgements This work was supported by the Ministry of Science and Technology of the People's Republic of China (2018ZX10711001, 2018ZX10734-404-003);National Key Research and Development Program (No.2018YFA0900800); National Science and Technology Major Project (2018ZX10102001); National Natural Science Foundation of China (31900156); Key Research and Development (R\&D) Projects of Shanxi Province, China (201803D31205); the United States National Institutes of Health U01 AI151810 and Development Grant of the State Key Laboratory of Infectious Disease Prevention and Control (2014SKLID103, 2015SKLID505).

Author Contributions QW and GL drafted and revised the manuscript. QW, SF, JC, XX, JW, BW, XT, YL, YH, FL, KN and SX participated in collection of sandfly specimens and acquisition of data. QW, SF, JC and GL participated in the analysis and interpretation of data. HW, XL and GL contributed to conception and design of the manuscript. All authors read and approved the final manuscript.

\section{Compliance with Ethical Standards}

Conflict of interest The authors declare no conflict of interests.

Animal and Human Rights Statement All animal experiments were conducted in strict compliance with the regulations set by the Animal Ethics Committee of China CDC.

\section{References}

Abudurexiti A, Adkins S, Alioto D, Alkhovsky SV, Avšič-Županc T, Ballinger MJ, Bente DA, Beer M, Bergeron É, Blair CD et al (2019) Taxonomy of the order Bunyavirales: update 2019. Arch Virol 164:1949-1965

Alkan C, Erisoz Kasap O, Alten B, de Lamballerie X, Charrel RN (2016) Sandfly-borne phlebovirus isolations from Turkey: new insight into the sandfly fever sicilian and sandfly fever naples species. PLoS Neg Trop Dis 10:e004519

Calzolari M, Chiapponi C, Bellini R, Bonilauri P, Lelli D, Moreno A, Barbieri I, Pongolini S, Lavazza A, Dottori M (2018) Isolation of three novel reassortant phleboviruses, Ponticelli I, II, III, and of Toscana virus from field-collected sand flies in Italy. Parasit Vectors 11:84

Cao L, Fu S, Gao X, Li M, Cui S, Li X, Cao Y, Lei W, Lu Z, He Y, Wang H, Yan J, Gao GF, Liang G (2016) Low protective efficacy of the current Japanese encephalitis vaccine against the emerging genotype 5 Japanese encephalitis virus. PLoS Neg Trop Dis 10: e0004686

Depaquit J, Grandadam M, Fouque F, Andry PE, Peyrefitte C (2010) Arthropod-borne viruses transmitted by Phlebotomine sandflies in Europe: a review. Euro Surveill 15:19507

Feng Y, Fu S, Zhang H, Li M, Zhou T, Wang J, Zhang Y, Wang H, Tang Q, Liang G (2012) Distribution of mosquitoes and mosquito-borne viruses along the China-Myanmar border in Yunnan Province. Jpn J Infect Dis 65:215-221

Feng Y, Li Y, Fu S, Li X, Song J, Zhang H, Yang W, Zhang Y, Pan H, Liang G (2017) Isolation of Kaeng Khoi virus (KKV) from Eucampsipoda sundaica bat flies in China. Virus Res 238:94-100

Feng Y, Ren X, Xu Z, Fu S, Li X, Zhang H, Yang W, Zhang Y, Liang G (2019) Genetic diversity of the Yokose virus, XYBX1332, isolated from bats (Myotis daubentonii) in China. Virol J 16:8

Folmer O, Black M, Hoeh W, Lutz R, Vrijenhoek R (1994) DNA primers for amplification of mitochondrial cytochrome c oxidase subunit I from diverse metazoan invertebrates. Mol Mar Biol Biotech 3:294-299

Fu S, Song S, Liu H, Li Y, Li X, Gao X, Xu Z, Liu G, Wang D, Tian Z, Zhou J, He Y, Lei W, Wang H, Wang B, Lu X, Liang G (2017) ZIKA virus isolated from mosquitoes: a field and laboratory investigation in China, 2016. Sci China Life Sci 60:1364-1371

Kuhn JH, Adkins S, Alioto D, Alkhovsky SV, Amarasinghe GK, Anthony SJ, Avšič-Županc T, Ayllón MA, Bahl J, BalkemaBuschmann A, et al. (2020) 2020 Taxonomic update for phylum Negarnaviricota (Riboviria: Orthornavirae), including the large orders Bunyavirales and Mononegavirales. Archives Virol 165:3023-3072

Liang G, Li X, Gao X, Fu S, Wang H, Li M, Lu Z, Zhu W, Lu X, Wang L, Cao Y, He Y, Lei W (2018) Arboviruses and their related infections in China: a comprehensive field and laboratory investigation over the last 3 decades. Rev Med Virol 28 
Maes P, Adkins S, Alkhovsky SV, Avšič-Županc T, Ballinger MJ, Bente DA, Beer M, Bergeron É, Blair CD, Briese T et al (2019) Taxonomy of the order Bunyavirales: second update 2018. Arch Virol 164:927-941

Ren X, Fu S, Dai P, Wang H, Li Y, Li X, Lei W, Gao X, He Y, Lv Z, Cheng J, Wang G, Liang G (2017) Pigsties near dwellings as a potential risk factor for the prevalence of Japanese encephalitis virus in adult in Shanxi. China Infect Dis Poverty 6:100

Shen S, Duan X, Wang B, Zhu L, Zhang Y, Zhang J, Wang J, Luo T, Kou C, Liu D, Lv C, Zhang L, Chang C, Su Z, Tang S, Qiao J, Moming A, Wang C, Abudurexiti A, Wang H, Hu Z, Zhang Y, Sun S, Deng F (2018) A novel tick-borne phlebovirus, closely related to severe fever with thrombocytopenia syndrome virus and Heartland virus, is a potential pathogen. Emerg Microbes Infect 7:95

Song S, Li Y, Fu S, Liu H, Li X, Gao X, Xu Z, Liu G, Wang D, Tian Z, Zhou J, He Y, Lei W, Wang H, Wang B, Lu X, Liang G (2017) Could Zika virus emerge in Mainland China? Virus isolation from nature in Culex quinquefasciatus, 2016. Emerg Micorbes Infect 6:e93
Tchouassi DP, Marklewitz M, Chepkorir E, Zirkel F, Agha SB, Tigoi CC, Koskei E, Drosten C, Borgemeister C, Torto B, Junglen S, Sang R (2019) Sand fly-associated phlebovirus with evidence of neutralizing antibodies in humans, Kenya. Emerg Infect Dis 25:681-690

Walker PJ, Siddell SG, Lefkowitz EJ, Mushegian AR, Adriaenssens EM, Dempsey DM, Dutilh BE, Harrach B, Harrison RL, Hendrickson RC, Junglen S, Knowles NJ, Kropinski AM, Krupovic M, Kuhn JH, Nibert M, Orton RJ, Rubino L, Sabanadzovic S, Simmonds P, Smith DB, Varsani A, Zerbini FM, Davison AJ (2020) Changes to virus taxonomy and the Statutes ratified by the International Committee on Taxonomy of Viruses (2020). Adv Virol 165:2737-2748

Wang J, Fu S, Xu Z, Cheng J, Shi M, Fan N, Song J, Tian X, Cheng J, Ni S, He Y, Lei W, Li F, Peng H, Wang B, Wang H, Lu X, Ma Y, Liang G (2020) Emerging sand fly-borne phlebovirus in China. Emerg Infect Dis 26:2435-2438

Yu X-J, Liang M-F, Zhang S-Y, Liu Y, Li J-D, Sun Y-L, Zhang L, Zhang Q-F, Popov VL, Li C et al (2011) Fever with thrombocytopenia associated with a novel bunyavirus in China. $\mathrm{N}$ Engl $\mathrm{J}$ Med 364:1523-1532 